INTERNATIONAL FOOD POLICY

RESEARCH INSTITUTE

sustainable solutions for ending hunger and poverty

A member of the CGIAR consortium

IFPRI Discussion Paper 01225

November 2012

\title{
Improving the Measurement of Food Security
}

\author{
Derek Headey \\ Olivier Ecker
}

Poverty, Health, and Nutrition Division

Development Strategy and Governance Division 


\section{INTERNATIONAL FOOD POLICY RESEARCH INSTITUTE}

The International Food Policy Research Institute (IFPRI) was established in 1975 to identify and analyze national and international strategies and policies for meeting the food needs of the developing world on a sustainable basis, with particular emphasis on low-income countries and on the poorer groups in those countries. IFPRI is a member of the CGIAR Consortium.

\section{PARTNERS AND CONTRIBUTORS}

IFPRI gratefully acknowledges the generous unrestricted funding from Australia, Canada, China, Denmark, Finland, France, Germany, India, Ireland, Italy, Japan, the Netherlands, Norway, the Philippines, South Africa, Sweden, Switzerland, the United Kingdom, the United States, and the World Bank.

\section{AUTHORS}

Derek Headey, International Food Policy Research Institute

Research Fellow, Poverty, Health, and Nutrition Division

D.Headey@cgiar.org

Olivier Ecker, International Food Policy Research Institute

Research Fellow, Development Strategy and Governance Division

\section{Notices}

IFPRI Discussion Papers contain preliminary material and research results. They have been peer reviewed, but have not been subject to a formal external review via IFPRI's Publications Review Committee. They are circulated in order to stimulate discussion and critical comment; any opinions expressed are those of the author(s) and do not necessarily reflect the policies or opinions of IFPRI.

Copyright 2012 International Food Policy Research Institute. All rights reserved. Sections of this material may be reproduced for personal and not-for-profit use without the express written permission of but with acknowledgment to IFPRI. To reproduce the material contained herein for profit or commercial use requires express written permission. To obtain permission, contact the Communications Division at ifpri-copyright@cgiar.org. 


\section{Contents}

Abstract $\quad$ V

Acknowledgments $\quad$ vi

1. Introduction 1

2. Calorie Deprivation Indicators 3

3. Monetary Poverty Indicators $\quad 7$

4. Dietary Diversity Indicators 9

5. Subjective/Experiential Indicators 13

6. Conclusions and Implications for Improving Food Security Measurement Systems 17

References $\quad 22$ 


\section{Tables}

2.1-Correlation matrix of food and nutrition security indicators for Malawi

3.1-Comparison of consumption estimates from household surveys and national accounts statistics

4.1 - Correlations between different indicators of food and nutrition security across countries

5.1-Bivariate associations (odds ratios) between HFIAS scores and stunting, undernutrition, and wasting in children six to 59 months of age

6.1-Usefulness of food and nutrition indicators in gauging the impacts of shocks: A score sheet 


\begin{abstract}
Although food security measurement has been substantially expanded in recent decades, there persists significant dissatisfaction with existing measurement systems, especially in the wake of the global food and financial crisis. In this paper we first set out a list of criteria that an ideal food security measurement system should satisfy. We then benchmark existing indicators and measurement systems against those criteria as a means of systematically identifying their relative strengths and weaknesses. Our concluding section outlines possible steps for improving food security measurement through a mixture of extension, coordination, and innovation.
\end{abstract}

Keywords: food security, nutrition security, food crisis, economic shock, climatic shock, measurement system 


\section{ACKNOWLEDGMENTS}

We are very grateful to the World Food Programme's Food Security Analysis Unit and particularly Claudia Ahpoe, Siemon Hollema, Joyce Luma, Kathryn Ogden, and Astrid Mathiassen for their insights into the WFP's food and nutrition security assessment. Jean-Francois Trinh Tan also provided excellent research assistance. We also thank Disha Ali and Michael Tedla of IFPRI for letting us report some of their results. And we are indebted to participants at the Food and Agriculture Organization's "International Scientific Symposium on Food and Nutrition Security Information: From Valid Measurement to Effective Decision-Making" (Rome, January 2012) and the International Association of Agricultural Economists' triennial meeting (August 2012). All errors are our own. 


\section{INTRODUCTION}

\section{"Measurement drives diagnosis and response. As global attention returns to food security, new opportunities emerge to improve its measurement."}

-Barrett (2010, 827)

Dissatisfaction with existing food security indicators is hardly new. Estimates of the prevalence of hunger (undernourishment) from the Food and Agriculture Organization of the United Nations (FAO) have been widely criticized for some time for lacking accuracy in both cross-sectional comparisons and trends (Gabbert and Weikard 2001; Nubé 2001; Smith 1998; Svedberg 1999, 2002). The World Bank's poverty estimates also have significant weaknesses for drawing cross-country comparisons and inferring global trends (Deaton 2010). The 2008 global food crisis - and the academic debate surrounding its impacts on poverty (Headey forthcoming; Swinnen 2010) — revealed an additional shortcoming: the inability of international agencies and national governments to monitor food security in a sufficiently accurate and timely manner. This shortcoming is also likely to become more costly in the near future. Food prices are predicted to remain high and volatile for the coming decade at least (OECD/FAO 2009; USDA 2009), and climate change could leave many countries more frequently exposed to severe weather events (IPCC 2012). Now, more than ever, then, there is an increased demand for the improved measurement of both food and nutrition security in the developing world.

It is less clear, however, how food security measurement should be improved. In addition to the obvious but underdiscussed issue of the costs of alternative measurement systems, the bewildering proliferation of food security indicators in recent years has provided greater variety but little consensus and insufficient coordination among different agencies. Moreover, although the justified mainstreaming of nutrition in the development dialogue has elevated nutrition security-particularly for infants in the first thousand days of life, and hence, for their mothers as well - to a critically important development goal (Nabarro 2010), there has been insufficient discussion of how food security measurement can be made more "nutrition sensitive."

In this paper we therefore reassess the direction that food security measurement should take by gauging the extent to which different indicators satisfy several key criteria. We motivate these criteria with a thought experiment that runs as follows. Imagine that you are a policymaker with a mandate for ensuring both food and nutrition security, either in a specific country or a set of countries. To perform your task optimally, you ideally need to empirically understand the spatial, temporal, and demographic dimensions of food insecurity in your country, and also how food insecurity contributes to malnutrition. You therefore need to know if food insecurity is worse in country A or country B. You need to know whether progress in country A is faster or slower than in country B. You need to know which parts of country A and B are most food insecure. You need to understand the seasonality of food insecurity in these countries and in particular areas of any given country. You need to understand the extent to which food insecurity is affected by various shocks, such as droughts, floods, or changes in incomes and prices. And for all of these spatial and temporal dimensions you ideally need to understand the demographic dimensions of food insecurity (such as the relative vulnerability of infants, children, and adults, of males and females, and of pregnant and breastfeeding women) as well as the epidemiology that links food intake to nutritional outcomes. The latter dimension would obviously refer to the relative importance of macroand micronutrient deficiencies, but also to interactions between diets, health burdens, childcare practices, and nutrition outcomes.

We would argue that, short of achieving this understanding of food and nutrition security in your portfolio of countries, you will not be able to accurately identify where and when there is a problem. You will also not be able to diagnose the causes of food insecurity and malnutrition if measurement is inaccurate. And if you cannot convincingly document and diagnose food and nutrition insecurity, there is also a good chance you will not be able to mobilize adequate resources for addressing the problem. At the very least, the allocation of those resources will be inefficient and perhaps very ineffective. In short, good 
measurement is a necessary (but insufficient) condition for accurate diagnosis and effective response, as the section-opening quotation from Barrett (2010) suggests.

Bearing this thought experiment in mind, the remainder of the paper focuses on the extent to which existing food security indicators and measurement systems fulfill the needs of our hypothetical national or international planner. Conceptually, we broadly accept the standard definition of food security as existing "when all people, at all times, have physical, social and economic access to sufficient, safe, and nutritious food to meet their dietary needs and food preferences for an active and healthy life" (FAO 1996). That said, we argue up front that food security definitions that incorporate psychological dimensions - such as anxiety over food consumption - threaten to dilute the paramount importance of the nutritional implications of food insecurity. We discuss these issues more later in the paper, but one telling example of the problems of subjective indicators is their irrelevance to issues of micronutrient deprivation, since that is very much a hidden hunger that is neither felt nor well understood among poorly educated populations. ${ }^{1}$

Methodologically, our approach to assessing the performance of different food security indicators draws upon a mix of literature review and fresh analysis of secondary data. One point of note is that we make a particular effort to be systematic in benchmarking the performance of different indicators against the implicit spatial and temporal dimensions mentioned earlier, as well as the relevance of those indicators to nutritional outcomes (including the ability of different indicators to measure outcomes for specific demographics). Another point of note is that, compared with previous reviews of food security measurement, we go much further in trying to assess the ability of different indicators to gauge the impacts of shocks, for the reasons outlined earlier.

The remainder of this paper is structured around four types of food security indicators: calorie deprivation (Section 2), monetary poverty (Section 3), dietary diversity (Section 4), and subjective/experiential indicators (Section 5 ). ${ }^{2}$ For each indicator class we identify the validity and consistency of the indicator with respect to cross-sectional and intertemporal dimensions, as well as the nutritional relevance of the indicator. In essence, we ask whether the indicator can yield valid and reliable data on the true differences between different states (that is, individuals, groups, countries, time periods) and on the contribution of food insecurity to malnutrition. We consider validity as the extent to which a concept, conclusion, or measurement is well founded and corresponds accurately to the real world, and reliability as the ability of an indicator to perform consistently, such as test-retest reliability. Admittedly, much of the existing research on food security indicators that we review often falls far short of the ideal in terms of providing any rigorous assessment of the statistical properties of the indicators. Indeed, such assessments should very much be a research priority in the future. Too often, research in this area tries to prove that an indicator works well, rather than to prove that it doesn't.

In our concluding remarks (Section 6) we summarize our findings and discuss what they imply for improving food security measurement, particularly at the global level. We conclude that the largest information gaps - and therefore the greatest gains from bridging them - pertain to three interconnected issues: the quality of diets (the need to go beyond calorie consumption); demographic dimensions (the need to go inside the household); and the frequency with which data are collected (the need to systematically gauge shocks and seasonality). We suggest that bridging these knowledge gaps requires scaling up resources in some areas, cutting them back in others, promoting much better interagency coordination, and scaling up the use of modern survey technologies.

\footnotetext{
${ }^{1}$ More generic response biases are another important problem with subjective indicators; they are discussed in more detail subsequently.

${ }^{2}$ Conceivably, other indicators could be considered here. For example, asset indexes are sometimes referred to as food security indicators, although we view them as conceptually too remote to the latent concept of food security, even if they bear a strong correlation with food security outcomes in practice. There are also composite indexes incorporating different food and nutrition security indicators such as the International Food Policy Research Institute's Global Hunger Index. We do not explicitly discuss such composite indexes since their strengths and weaknesses emerge from the individual indicators used.
} 


\section{CALORIE DEPRIVATION INDICATORS}

Calorie availability or deprivation is one of the oldest indicators of food insecurity. It is measured by the FAO at the country level based on national food balance sheets, ${ }^{3}$ but it is also measured at the household level from expenditure and consumption data available in standard economic surveys such as the World Bank's Living Standards Measurement Study. To distinguish between them we will hereafter refer to the two types as the FAO indicator and household calorie consumption indicators.

\section{Cross-Sectional Validity}

Unlike all of the other food security indicators discussed here, the FAO indicator of calorie deprivation is measured solely at the national level. This largely stems from necessity since this indicator is derived from national food availability estimates (that is, production plus net imports less storage and wastage reported in the food balance sheets), which are then given an artificial distribution based on food consumption data from occasional household surveys, and demographically adjusted estimates of minimum calorie requirements (FAO 2003).

The numerous assumptions built into this approach have long formed the basis for most of the criticism directed at the FAO measure (Gabbert and Weikard 2001; Nubé 2001; Smith 1998; Svedberg 1999, 2002). However, in principle, household survey data of food consumption could be used to measure the proportion of a population with inadequate calorie consumption (as in Smith, Alderman, and Aduayom 2006). Even so, it is an open question as to whether household surveys or national food balance sheets provide better estimates at the aggregate level. Both face sizable measurement error, albeit from different sources. The FAO must often rely on plainly unreliable national data sources, with data on wastage and storage being particularly circumspect. Household survey data are instead flawed by recall errors, biases, and choice of survey instrument (Beegle et al. 2012), as well as more specific problems related to food consumed outside the home, wastage and storage, and food given to animals, employed laborers, or guests (Bouis, Haddad, and Kennedy 1992; Bouis 1994). The defining difference with the FAO indicator, however, is that the distribution of calories over the population is simulated from household income or expenditure data rather than observed directly. Furthermore, the inability of the FAO approach to yield estimates for subnational groups clearly limits the policy relevance of the indicator.

\section{Nutritional Relevance}

Insofar as calorie indicators are not commonly or easily measured at the individual level, their nutritional relevance is clearly limited. Even so, if household calorie consumption were a strong predictor of individual nutrition outcomes we might be much less concerned at the inability of these indicators to measure individual-level outcomes. Yet in many countries there appears to be either a very weak correlation or no correlation between calorie deprivation and anthropometric indicators of malnutrition. Deaton and Drèze (2009) find this for India, and Pelletier et al. (1995) reach the same conclusion for Ethiopia. As Table 2.1 - a correlation matrix between a range of food security and nutrition indicatorsshows, we also found no significant correlation between household calorie consumption and child heightfor-age and weight-for-age z-score in Malawi. ${ }^{4}$ Although one cannot rule out the possiblity that anthropometric indicators are also flawed, other food security indicators at least achieved statistically significant correlations with such anthropometric indicators. Thus household calorie consumption seems to be a poor predictor of individual nutrition outcomes.

3 See de Haen, Klasen, and Qaim (2011) for an overview. Note that the FAO's methodology is being revised to make use of a larger number of recent household expenditure and consumption surveys among others (FAO 2011).

4 Though not shown, we found the same results for Yemen using data from the Household Budget Survey 2005/06. 
Table 2.1—Correlation matrix of food and nutrition security indicators for Malawi

\begin{tabular}{|c|c|c|c|c|c|c|c|c|c|c|c|c|c|c|}
\hline Household food security & \multicolumn{2}{|c|}{ SAFA } & \multicolumn{2}{|c|}{ EXP } & \multicolumn{2}{|c|}{ FVS } & \multicolumn{2}{|c|}{ DDS } & \multicolumn{2}{|l|}{ CALC } & \multicolumn{2}{|l|}{ HAZ } & \multicolumn{2}{|c|}{ WHZ } \\
\hline Self-assessed food adequacy, binary (SAFA) ${ }^{a}$ & 1.000 & & & & & & & & & & & & & \\
\hline Expenditure per capita, log (EXP) & 0.254 & $* * *$ & 1.000 & & & & & & & & & & & \\
\hline Food variety score $(F V S)^{b}$ & 0.153 & $* * *$ & 0.477 & $* * *$ & 1.000 & & & & & & & & & \\
\hline Dietary diversity score $(\mathrm{DDS})^{\mathrm{c}}$ & 0.209 & $* * *$ & 0.494 & $* * *$ & 0.828 & $\star * *$ & 1.000 & & & & & & & \\
\hline Calorie consumption per capita, log (CALC) ${ }^{d}$ & 0.096 & *** & 0.591 & $\star * *$ & 0.281 & *** & 0.250 & $* * *$ & 1.000 & & & & & \\
\hline Childhood nutrition $^{\mathrm{e}}$ & & & & & & & & & & & & & & \\
\hline Height-for-age z-score (HAZ) & 0.093 & $* * *$ & 0.050 & $* * *$ & 0.051 & $* * *$ & 0.068 & $* * *$ & 0.012 & & 1.000 & & & \\
\hline Weight-for-height z-score (WHZ) & 0.048 & $* * *$ & 0.051 & $* * *$ & 0.027 & * & 0.044 & $* * *$ & 0.014 & & -0.157 & $* * *$ & 1.000 & \\
\hline Weight-for-age z-score (WAZ) & 0.106 & $* * *$ & 0.076 & $* * *$ & 0.057 & $* * *$ & 0.086 & $* * *$ & 0.061 & * & 0.650 & $* * *$ & 0.598 & $* * *$ \\
\hline
\end{tabular}

Source: Based on Malawi Second Integrated Household Survey 2004-2005.

Notes: ' $\quad$ Question: 'Concerning your household's food consumption over the past one month, which of the following is true?' Answer: 'It was 'less than adequate' (1), 'just adequate' (2), 'more than adequate' (3) for household needs; while "note that 'adequate' means no more or no less than what the respondent considers to be the minimum consumption needs of the household." Households with 'just adequate' and 'more than adequate' food consumption are combined.

${ }^{\mathrm{b}}$ Condiments were excluded from the count.

${ }^{\mathrm{c}}$ The maximum score includes 12 food groups.

${ }^{\mathrm{d}}$ Outliers (with calorie consumption less than 500 kilocalories and more than 5,000 kilocalories) were dropped.

${ }^{\mathrm{e}}$ Anthropometrics are for children aged six to 59 months.

$* * *, * * *$ Coefficient is statistically significant at the $1 \%, 5 \%$, and $10 \%$ level, respectively. 


\section{Intertemporal Validity}

To what extent is calorie deprivation a valid and reliable indicator of trends, the impacts of shocks, and seasonality? The FAO indicator has long been used to gauge trends in global hunger, and some developing countries also focus considerable attention on trends in household calorie consumption levels, notably India. Although the extent of calorie deprivation in a population was for many years accepted as a fairly reliable indicator of material progress, a number of recent works have called that into question, particularly in the Indian and Chinese contexts. In India, survey-based indicators have suggested that calorie consumption has declined, despite rapid economic growth and monetary poverty reduction. This apparent paradox has raised serious concerns about the usefulness of this indicator. One problem may be sheer measurement error, due to the increasing share of food consumed outside the home, for example. Indeed, the FAO indicator does not suggest a decline in calorie availability (Headey, Chiu, and Kadiyala 2012). Another explanation, however, could be the declining energy requirements of individuals in dynamic economies (Deaton and Drèze 2009; Headey, Chiu, and Kadiyala 2012). This can occur because of reduced physiological energy expenditure related to improved infrastructure and mechanization (from increased use of cars, motorbikes, tractors, and piped water, for example) and reduced energy losses through improved healthcare.

In addition, Jensen and Miller (2010) argue that calorie availability is a particularly poor indicator of trends in food security because of the very low income and own-demand elasticities of staple foods. For example, aggregate calorie consumption may not rise substantively with income gains because people quickly shift to a maximum of improving the taste of their food bundle rather than one of maximizing total calorie intake (Jensen and Miller 2010). It is particularly disconcerting that these arguments have been applied to India and China — the two most populous countries in the world - which would appear to warrant low confidence in global hunger estimates.

Finally the responsiveness of calorie availability indicators to shocks is very much open to question. In the 2008 crisis the FAO did not have sufficiently timely data to even simulate the impacts of higher food prices on calorie deprivation, demonstrating that its method is ill suited to gauging the impacts of shocks. It therefore relied on estimates produced by a production and trade model developed by the US Department of Agriculture (USDA) for low-income countries only. However, the estimated increases in hunger - with the global estimate eventually exceeding one billion hungry people worldwide in 2009 (FAO 2009) - were later contradicted by the FAO and the USDA's own survey-based estimates of national food availability (Headey forthcoming).

More generally there are strong theoretical and empirical reasons to believe that calorie availability is a very poor gauge of the impacts of idiosyncratic or covariate shocks. The theoretical arguments are threefold. First, as per Jensen and Miller (2010), when poor people suffer a loss of income, they switch from high-value calorie sources (for example, meat) to low-value calorie sources (for example, rice). Thus although total food expenditure may decline significantly, calorie consumption might not. Second, people may sacrifice nonfood expenditure to maintain calorie consumption levels. Third, many poor people produce their own food staples, and thus may choose to rely more on the consumption of foods from their own farm when market prices increase prohibitively.

Reviewing the literature of the 1998 Indonesian financial crisis, we find substantive empirical evidence for these three arguments. That crisis led to a nearly 200 percent increase in rice prices, yet all of the existing evidence suggests that rice consumption was maintained or perhaps even increased slightly (Skoufias 2003). In contrast, the consumption of high-value foods declined precipitously according to most surveys (Block et al. 2004; Hartini et al. 2003b), as did nonfood expenditures (Frankenberg, Thomas, and Beegle 1999). ${ }^{5}$ Interestingly, the FAO data also show no decline in food availability at the aggregate level in Indonesia over the course of the crisis (indeed, this was a criticism of the indicator at the time; see FAO 2003). For Bangladesh there is similar evidence based on high-frequency (monthly) data from the Nutrition Surveillance System over 1991 to 2000 (Torlesse, Kiess, and Bloem 2003).

\footnotetext{
${ }^{5}$ There is also some suggestion that rural households were better able to cope with the crisis than urban households thanks to a higher share of food from own production.
} 
Specifically, as rice prices fluctuated quite markedly, rice expenditures persisted, whereas nonrice food expenditures varied negatively with rice prices. Whereas these examples are derived from dynamic (panel or pseudo-panel) data on sizable economic shocks, Jensen and Miller (2010) reach the same conclusion from a randomized experiment on Chinese data. The conclusion from all of this work is that calorie availability is a very poor indicator of the impacts of shocks, except perhaps in situations of the most severe food shortages (that is, famines). 


\section{MONETARY POVERTY INDICATORS}

Monetary poverty is a somewhat more indirect indicator of people's economic access to food, given the additional necessity of purchasing important nonfood items. Indeed, potential substitution between the demand for food and nonfood items is an important rationale for viewing poverty indicators as preferable to food- or calorie-based indicators. As per the preceding discussion, higher food prices might not reduce calorie consumption but could significantly reduce nonfood expenditures, thereby raising poverty. For this reason many economists still advocate monetary poverty as an attractive indicator of food insecurity. Moreover, absolute poverty lines are usually linked to minimum calorie consumption requirements, providing a potentially important empirical link to food insecurity. In practice, however, poverty lines often become delinked over time (for example, Deaton and Drèze 2009 on India). Moreover, poverty indicators have received substantial criticism in recent years on several other counts related to their crosssectional and intertemporal validity.

\section{Cross-Sectional Validity}

Most of the criticism in terms of lacking cross-country comparability of monetary poverty indicators has focused on issues of converting household expenditures into a common international currency via purchasing power parity (PPP) conversion (Deaton 2010; Deaton and Dupriez 2011). Although they are an improvement over exchange rates, PPPs are not typically derived from the consumption patterns of poor populations (with the exception of Deaton and Dupriez 2011). A second underemphasized problem - perhaps related to the fact that little can be done about it — is measurement error. Experimental research on survey design has demonstrated that the choice of survey instrument matters substantively to expenditure-based results (Beegle et al. 2012). But more generally, there are indications of sizable measurement error in household survey data from some developing countries that is largely related to the limited capacity of the statistical institutions. An indication of this is the extent to which mean per capita consumption from household surveys varies to mean consumption from national accounts. Clearly, national accounts data are also measured with error, but Table 3.1 shows a disturbing variation in the ratio of the two indicators. In Indonesia, for example, survey-based consumption is just 40 percent of national accounts-based consumption, but the equivalent ratio for the Congo is 169 percent.

What about issues of comparability within countries? Here, too, substantive issues exist related to the pricing comparisons across space. For example, there are widespread concerns about the comparability of rural and urban poverty in India (Deaton and Drèze 2002). And in some countries we see much larger gaps in malnutrition than in poverty. For example, in Ethiopia the government's main household economic survey suggested a 5-percentage-point rural-urban gap in \$1.25-a-day poverty, but the gap in child stunting was 17 percentage points. There are several explanations for this discrepancy. First, a bias may occur from the difficulties of pricing subsistence consumption. Second, unobserved seasonal shortfalls are a major issue in rural areas but much less so in urban areas. Third, monetary poverty indicators perform poorly in capturing access to and quality of essential services that are important for nutrition such as health, education, and family planning services. Our conclusion is therefore that, in principle, monetary poverty indicators are a very good indicator of food security, but in practice they fall far short of the ideal. 
Table 3.1-Comparison of consumption estimates from household surveys and national accounts statistics

\begin{tabular}{lccc}
\hline Country & Mean yearly consumption (2005 PPP\$) & $\begin{array}{c}\text { Survey mean as ratio } \\
(\%) \\
\text { accounts mean }\end{array}$ \\
\cline { 1 - 2 } China & 1,295 & 1,752 & $74 \%$ \\
South Africa & 3,131 & 5,872 & $53 \%$ \\
Yemen & 1,008 & 1,435 & $70 \%$ \\
Indonesia & 905 & 2,257 & $40 \%$ \\
Pakistan & 809 & 1,989 & $41 \%$ \\
Ghana & 966 & 949 & $102 \%$ \\
Senegal & 802 & 1,342 & $60 \%$ \\
Ethiopia & 617 & 460 & $134 \%$ \\
India & 642 & 1,427 & $45 \%$ \\
Kenya & 786 & 1,195 & $66 \%$ \\
Niger & 657 & 463 & $142 \%$ \\
Bangladesh & 584 & 985 & $59 \%$ \\
Uganda & 632 & 762 & $83 \%$ \\
Madagascar & 538 & 731 & $74 \%$ \\
Rwanda & 514 & 607 & $85 \%$ \\
Congo, DR & 261 & 154 & $169 \%$ \\
\hline
\end{tabular}

Source: Calculated from PovCal data of the World Bank (2012), while the last two columns also use International Comparison Program data of the World Bank (2008) based on consumption from the National Accounts System.

Notes: ${ }^{\mathrm{a}}$ Indian data refer to 2004 rather than 2005. $\mathrm{PPP}=$ purchasing power parity.

\section{Intertemporal Validity}

As we have noted, household consumption surveys are expensive and therefore infrequent. This leaves them little or no potential to examine seasonality. Gauging the extent of major shocks is difficult with infrequent data and has forced a reliance on simulation approaches to predict the poverty impacts of economic crises using precrisis survey data (for example, Ivanic and Martin 2008; de Hoyos and Medvedev 2009; Ivanic, Martin, and Zaman 2011), following the approach of Deaton (1989). Essentially this net benefit approach relies on the idea that the effects of price changes on disposable income depend on whether a household is a net food producer or net food consumer. Although such an approach is insightful in some regards, it involves assumptions of questionable validity. For example, it is not obvious that income and price elasticities observed in normal times (typically in cross-sections) apply to the coping behaviors adopted during economic crises. Moreover, the simulation approaches used in the 2008 food crisis predicted rising global poverty (Ivanic and Martin 2008; de Hoyos and Medvedev 2009), whereas historical data suggested sizable reductions in poverty (World Bank 2012). Thus it is far from obvious that simulation models are good predictors of actual welfare changes.

The expensive solution to this problem would be to conduct household surveys in higher frequency. Certainly, evidence from the Indonesian financial crisis suggests that high-frequency household surveys are a good means of gauging the expenditure impacts of shocks and even of some of the specific coping mechanisms involved. But apart from the sheer financial costs, timing is another issue. For example, some surveys conducted late on in the Indonesian financial crisis found little or no harmful impacts (Ngwenya and Ray 2007), whereas surveys conducted at the peak of the crisis found more adverse impacts (Frankenberg, Thomas, and Beegle 1999). 


\section{DIETARY DIVERSITY INDICATORS}

Theoretical and empirical evidence suggests that dietary diversity indicators might be surprisingly effective food and nutrition security indicators, for two basic reasons. First, standard definitions of both food and nutrition security emphasize the importance of both macro- and micronutrients (FAO 1996). In principle, dietary diversity should capture consumption of both types of nutrients, or a more balanced diet more generally (Ruel 2003). Second, economic theories of demand - as well as psychological theories such as Maslow's hierarchy of needs (Maslow 1943) — suggest that individuals will diversify into highervalue micronutrient-rich foods (such as meats, fish, eggs, dairy products, and to a lesser extent fruits and vegetables) only when they have satisfied their basic calorie needs. In other words, as poor people become richer, they gravitate away from relatively tasteless staple foods toward micronutrient-rich foods that impart greater taste, and therefore utility (Jensen and Miller 2010).

For these reasons, and because of their relative cost-effectiveness, dietary diversity indicators have become increasingly popular in recent years, particularly in health and nutrition surveys such as the Demographic and Health Surveys, but also in the World Food Programme's (WFP's) Emergency Food Security Assessments. As a general class, these indicators essentially consist of answers to recall questions about the consumption of particular food items or groups over a recent period ranging typically from one day up to two weeks. The most common indicators are the food variety score (FVS), the dietary diversity score (DDS), and the food frequency score (FFS). The FVS provides a count of the number of different food items consumed, and the DDS the number of different food groups-usually anywhere between 7 and 15 food groups. The FFS is based on recalls that ask how often a food group was consumed over the given time period. In some sense, the simple count indicators (FVS and DDS) are special cases of the FFS, so for simplicity we refer to all of them as dietary diversity indicators.

One of the most widely used DDS measures at the household level is the 12-scale Household Dietary Diversity Score developed by the Food and Nutrition Technical Assistance (FANTA) Project of the United States Agency of International Development (USAID) (Swindale and Bilinsky 2006a, 2006b). Recently the FAO has promoted a modified, 9-scale version - especially for assessing women's food and nutrition security - that differs from FANTA's DDS by dropping the nonstaple, micronutrient-poor food groups (such as fats and sugars) and regrouping vegetables, fruits, and animal products according to their bioavailable vitamin A and iron contents (Kennedy, Ballard, and Dop 2011).

The WFP's food consumption score (FCS) is a frequency-weighted dietary diversity score that is calculated from a seven-day household food consumption recall available from the WFP's Comprehensive Food Security and Vulnerability Analysis (CFSVA) surveys. The FCS attaches greater importance to foods deemed most important for nutritional purposes (WFP 2008). The highest weights are attached to meat, fish, and milk (4), followed by pulses (3), cereals (2), vegetables and fruits (1), and sugar and oil (0.5). The FCS also omits condiments that are consumed in very small quantities and have no significant beneficial impact on the overall diet (such as tea, coffee, salt, fish powder, or very small amounts of milk added to tea or coffee). Since the weights are applied after data collection, the final FCS could be altered to vary the emphasis on macro- and micronutrients.

\section{Cross-Sectional Validity}

A number of relatively recent studies have explored the validity of these indicators in a cross-sectional sense. Ruel (2003) provided an extensive review of validation studies of dietary diversity indicators from 1996 to 2002. She generally found positive and fairly strong associations between DDS or FVS and macro- and micronutrient adequacy in developing countries. For example, a study from urban areas in Mali shows correlation coefficients between FVS and nutrient adequacy of 0.33 and between DDS and nutrient adequacy of 0.39 (Hatloy, Torheim, and Oshaug 1998). A similar study for rural areas in Mali shows correlation coefficients of 0.34 and 0.30 , respectively (Torheim et al. 2004). Other studies from South Africa and the Philippines report even higher correlation coefficients of up to 0.72 (Kennedy et al. 2007; Steyn et al. 2006). 
Other studies have examined statistical relationships between dietary diversity indicators and calorie and food expenditure. A 10-country study by Hoddinott and Yohannes (2002) found that a 1 percent increase in household dietary diversity is associated with a 1 percent increase in household consumption, a 0.7 percent increase in total household calorie consumption, a 0.5 percent increase in household calorie consumption from staples, and a 1.4 percent increase in household calorie consumption from nonstaples. A study by Wiesmann et al. (2009) tested the correlation between the WFP's FCS and household calorie consumption in Burundi, Haiti, and tsunami-affected areas of Sri Lanka using sevenday household food consumption data. Unlike most previous studies, this study varied the number of food groups included, the weights attached to food groups, and the degree of truncation of very small consumption quantities. Wiesmann et al. (2009) found that although the original FCS is moderately correlated with calorie consumption (with coefficients of 0.27 in Burundi and 0.44 in Haiti), there is little or no advantage in applying weights or frequencies to particular food groups, though there were some advantages to using more disaggregated food groups, and substantial advantages to excluding small quantities (indeed, correlations with household calorie consumption rose to 0.70 in one instance). Thus, consistent with other studies (for example, Arimond and Ruel 2006), dietary diversity indicators appear to be generally more nutritionally meaningful — in terms of both macro- and micronutrient adequacy — when omitting extremely small food quantities.

These findings suggest that dietary diversity indicators are relatively valid across households within countries, thus providing some validation for their policy use by the WFP. Yet we know of no study that explores the validity of such indicators in making cross-country comparisons. The principal obstacle to doing so is related partly to lack of coordination and dissemination of dietary diversity data, and partly to the challenge of measuring diversity across countries when diets vary markedly. For example, pulses are an important source of calories, protein, and some minerals in some countries (for example, South Asia) but in other countries are a much less important part of the diet. Another constraint is that thus far no rigorous approach exists for deciding how cutoff levels should be selected so as to identify moderate or severe dietary inadequacy.

We conjecture, however, that these constraints are not insurmountable, and that the limitations of dietary diversity indicators need to be compared with their cost-effectiveness. Table 4.1 provides some evidence that dietary diversity may be more comparable across countries than previously thought. Specifically, we used the FAO food balance sheets to construct a very simple measure of dietary diversity: the share of calories from nonstaple foods, where staple foods consist of cereals and root crops. We then compared how that indicator correlates with other food and nutrition security indicators across countries. Since there is no gold standard for food and nutrition security measurement, we have to interpret the results cautiously, but a stark result from Table 4.1 is that this exceedingly simple dietary diversity indicator correlates more strongly with anthropometric indicators of malnutrition than the FAO calorie deprivation indicator. In fact, the latter does not correlate significantly with low maternal body mass index (BMI) at all and has only a very weak correlation with child wasting. This suggests that dietary diversity indicators could well be satisfactorily valid in a cross-country setting, especially with better data and further refinement of the indicators. 
Table 4.1-Correlations between different indicators of food and nutrition security across countries

\begin{tabular}{|c|c|c|c|c|c|c|c|}
\hline & $\begin{array}{c}\text { Calories } \\
\text { per capita }\end{array}$ & $\begin{array}{c}\text { Diet } \\
\text { diversity }\end{array}$ & $\begin{array}{c}\$ 1.25-a-d a y \\
\text { poverty }\end{array}$ & $\begin{array}{c}\text { Calorie } \\
\text { deprivation }\end{array}$ & $\begin{array}{c}\text { Child } \\
\text { stunting }\end{array}$ & $\begin{array}{c}\text { Child } \\
\text { wasting }\end{array}$ & $\begin{array}{c}\text { Low maternal } \\
\text { BMI }\end{array}$ \\
\hline $\begin{array}{l}\text { Calories per } \\
\text { capita }\end{array}$ & 1 & & & & & & \\
\hline Diet diversity & 0.26 & 1 & & & & & \\
\hline Poverty & $-0.63^{* *}$ & $-0.55^{\star *}$ & 1 & & & & \\
\hline $\begin{array}{l}\text { Calorie } \\
\text { deprivation }\end{array}$ & $-0.46^{* *}$ & $-0.30^{*}$ & $0.71^{* *}$ & 1 & & & \\
\hline Stunting & $-0.53^{* *}$ & $-0.63^{\star *}$ & $0.68^{* *}$ & $0.51^{* *}$ & 1 & & \\
\hline Wasting & -0.07 & $-0.58^{* *}$ & $0.38^{* *}$ & $0.28^{*}$ & $0.45^{\star *}$ & 1 & \\
\hline $\begin{array}{l}\text { Low BMI, } \\
\text { maternal }\end{array}$ & -0.21 & $-0.47^{* *}$ & $0.31^{*}$ & 0.08 & $0.47^{* *}$ & $0.77^{* *}$ & 1 \\
\hline
\end{tabular}

Source: Calculated from the FAO's food balance sheets, World Bank's World Development Indicator database (World Bank 2012), and the Demographic Health Surveys. The sample size is around 60 countries, depending on the variable pairs.

Notes: $\quad * * *$ Coefficient is statistically significant at the $5 \%$ and $10 \%$ level, respectively; BMI = body mass index.

\section{Intertemporal Validity}

It is well known that dietary diversity improves over economic development (Bennett's law), suggesting that dietary diversity indicators are well suited to tracking slow-moving trends in food and nutrition security. However, we know of only one study that provides a specific analysis of the responsiveness of dietary diversity indicators to shocks and seasonality. Brinkman et al. (2010) analyzed several WFP datasets, some of which tracked changes in the FCS over a period of a few months during the 2008 global food price crisis. They find reduced dietary diversity (as measured by the FCS) in most cases. The authors also estimated elasticities of the FCS with respect to local staple food price changes for Haiti, Nepal, and Niger and find significant elasticities varying between 0.05 and 0.21 . Hence their results seem to show that the FCS displays substantial sensitivity to shocks, though in some cases not as much as one would like. ${ }^{6}$

Additional evidence on dietary diversity comes from the aforementioned analyses of monthly data from Nutrition Surveillance System surveys in Indonesia and Bangladesh. Over the course of Indonesia's 1998 financial crisis Bloem, de Pee, and Darnton-Hill (2005) and Block et al. (2004) report substantially declining dietary diversity in Indonesia, particularly reduced consumption of egg products. ${ }^{7}$ Strikingly, Block et al. (2004) conclude that reduced consumption of micronutrient-rich foods accounts for an 18-point increase in child anemia prevalence. And over a much longer period in Bangladesh (1990-1999), Torlesse, Kiess, and Bloem (2003) found that dietary diversity fluctuates with rice prices (negatively), which in turn correlates with child underweight prevalence (negatively).

Finally, there are some indications that dietary diversity indicators may also be able to pick up seasonal variations in food consumption. Specifically, Savy et al. (2006) found for women living in the Sahel in Burkina Faso that the DDS is sensitive to seasonal variations in food consumption, while the relationship between women's BMI and dietary diversity is also seasonal and likely influenced by changing relevance of socioeconomic factors and varying workloads.

\footnotetext{
${ }^{6}$ We should add a caveat to that result. Brinkman et al. (2010) do not use a preferred regression framework in our view, since they use logs of levels rather than first differences. A differenced model would remove fixed effects, which could be causing simultaneity biases in the regressions. Moreover, the sample sizes for two of the countries (Haiti and Nepal) are small enough (500 to 600 households) to suggest that they are not nationally representative. And, perhaps most critically, there is no means of distinguishing between net-food-producing and net-food-consuming households. Clearly net-food-producing households might benefit from higher food prices.

${ }^{7}$ A smaller panel survey from Java also reports decreased meat consumption (Hartini et al. 2003a, 2003b).
} 


\section{Nutritional Relevance}

A distinct advantage of dietary diversity indicators over calorie deprivation and poverty indicators is that they can be asked about individuals as well as households. Indeed, the Demographic and Health Surveys have thus far only collected dietary diversity data for mothers and children (as reported by mothers), though there are a few surveys that pose the question at both the household and individual level. ${ }^{8}$ Ruel's review (2003) revealed a consistent positive association between dietary diversity indicators and child growth and nutritional status in a number of countries. A subsequent study by Arimond and Ruel (2006) tested whether the Demographic and Health Surveys' dietary diversity indicator could explain childhood stunting in 11 countries, and found it to be a significant explanatory variable in all but one country. ${ }^{9}$ In Table 2.1 we also saw that dietary diversity indicators have significant associations with all three child anthropometric indicators. Thus dietary diversity indicators seem to be quite a nutrition-relevant indicator of food security.

\footnotetext{
${ }^{8}$ Unpublished work from two recent IFPRI studies tends to find a strong correlation between household and individual.

${ }^{9}$ In several cases the indicator was significant only when interacted with other terms, although such interactions are often intuitive (such as interactions with the age of the child).
} 


\section{SUBJECTIVE/EXPERIENTIAL INDICATORS}

A final class of indicators is subjective indicators - sometimes called experiential indicators - in which respondents are asked to rate the depth or frequency of their food insecurity. At one extreme are very simple dichotomous indicators, such as the Gallup World Poll indicator used by Headey (forthcoming), which asked whether respondents had experienced problems affording food over the previous 12 months. Other surveys - including the Afrobarometer survey, the WFP's CFSVA survey, the World Bank's Core Welfare Indicator Questionnaire survey, and some household consumption and expenditure surveyscontain questions about the frequency of food affordability problems or experiences of hunger in the last 12 months.

At the extreme of sophistication in experiential indicators of food security is the Household Food Insecurity and Access Scale (HFIAS) developed by USAID's FANTA project. The HFIAS is an adaptation of the Household Food Security Survey Module scale, used by the USDA and other agencies to measure food access in the United States. Respondents are asked to assess the frequency of different types/degrees of food insecurity over a four-week recall period, including experiences related to anxiety about household food access, satisfaction of food preferences, food availability and diversity, and signs of food shortages in daily life. The answers to the nine questions yield a rank on the HFIAS that captures the full breadth of insecurity from the purely psychological to more physical feelings of hunger (Coates, Swindale, and Bilinsky 2007).

\section{Cross-Sectional Validity}

Compared with the indicators discussed previously, subjective indicators possess some unique advantages and disadvantages. Advantageously, subjective indicators can capture psychological dimensions of food insecurity. Although we would argue that the nutritional implications of food insecurity should be paramount in underdeveloped settings, psychological dimensions are often of inherent interest, since perceptions matter in their own right. Subjective data can also be useful for gauging expectations, such as inflation expectations (based on forward-looking questions about food security, for example). A second advantage is the relatively low cost of subjective data, especially compared with time-consuming expenditure data required to compute poverty and calorie consumption estimates. A third advantage is that subjective recall questions can be used to capture seasonality, such as through the "hunger gap" question, which asks about the number of months or weeks of hunger experienced in the last year.

These advantages have prompted substantial enthusiasm in the nutrition community (particularly for the HFIAS), but there are thus far surprisingly few critiques of subjective indicators from economists, who are traditionally wary of response biases and the lack of any common reference frame in subjective questions. Although there is a sizable economic literature on the weaknesses of subjective indicators, very little of it applies to food security questions specifically. The literature that does exist, however, raises some important concerns. Deaton (2011) and Headey (forthcoming) found that the ordering of questions significantly affected responses in two different Gallup surveys. Deaton found that the bias induced by question ordering in a high-frequency Gallup poll of US citizens had a larger influence on self-reported well-being than the recent financial crisis. Headey (forthcoming) found that question ordering appeared to have a large effect on self-reported food insecurity in China. His paper also raised concerns about lack of comparability of self-assessed food insecurity across wealth and education groups because of different individual dietary standards or reference points. In particular, he found that self-reported food insecurity was surprisingly high in some middle-income countries with exceptionally high rates of educational attainment (including Sri Lanka and a number of Central Asian countries).

Another issue related to cross-section validity is cross-cultural inconsistency. Deitchler et al. (2010) tested the cross-cultural comparability of the HFIAS scale in six countries and found that only three of the nine questions in the HFIAS demonstrated adequate cross-country comparability. Specifically, those were the last three questions pertaining to experiences of hunger and their physical consequences: "no food to eat of any kind"; "go to sleep hungry at night"; and "go a whole day and night 
without eating." In retrospect, perhaps this result is not so surprising, since the meaning of these "terms" is less open to interpretation than terms included in the first six questions of the HFIAS, such as "worry," "enough food," "preferred food," "variety of foods," and so on..$^{10}$ It seems likely that such terms don't elicit a sufficiently clear reference frame. For example, "variety" for a poor person may involve eating animal-sourced products once a month, but for a wealthy person it may involve eating such products once a day.

Although the Deitchler et al. (2010) study is certainly informative, it makes little mention of other possible sources of response bias. Possible sources of underestimation of food insecurity include feelings of shame associated with admitting hunger, or fear (particularly in authoritarian regimes where even implicit criticisms of government policies are not tolerated). And possible sources of overestimation of food insecurity include the increasing scope of public transfers (food aid, social safety nets, or other welfare programs), which foster material incentives for individuals to classify themselves as food insecure.

These rather negative conclusions from the food security literature on subjective indicators prompted us to look at how subjective indicators correlate with other food security and nutrition indicators, using household survey data from Malawi, Cambodia, and Ethiopia. For Malawi we correlated a binary variable of subjective household food adequacy with household expenditure and calorie consumption per capita (in logarithmic terms) as well as dietary diversity indicators and child anthropometrics (Table 2.1). For Cambodia we used the Cambodia Socio-Economic Survey 2009 to calculate the coefficients for correlations with the binary household food adequacy variable and the hunger gap indicator (measured on a weekly basis). For Ethiopia we used the hunger gap indicator (measured on a monthly basis) from the Welfare Monitoring Survey 2004-2005 and correlated it with household food expenditure and calorie consumption per capita.

For Malawi and Cambodia, the strongest correlation of subjective household food adequacy is with household expenditure (with coefficients of 0.25 and 0.22 , respectively), followed by the DDS (with coefficients of 0.21 and 0.16 , respectively). However, the correlation of subjective food security indicators with calorie consumption is low in Malawi (with a coefficient of 0.10 ) and even statistically insignificant for Ethiopia. ${ }^{11}$ For Malawi and Cambodia the correlations of the subjective household food adequacy indicator with anthropometric indicators are low (less than 0.11) but statistically significant (with the exception of weight-for-height z-scores for Cambodia), and no lower than the correlations that other food security indicators share with anthropometric indicators. For Cambodia the hunger gap indicator yields slightly lower correlation coefficients with all quantitative food and nutrition security indicators than the binary household food adequacy indicator. In Ethiopia the correlation between the hunger gap indicator and household food expenditure is much lower (with a coefficient of -0.04). Overall, then, the results are somewhat mixed: there are some reasonably strong associations between subjective indicators and other food and nutrition security indicators, but many correlation pairings are quite weak.

Our overall conclusion is that subjective indicators have some potential to measure meaningful information on food security, particularly on extreme forms of hunger. There may also be substantial means of improving their measurement. ${ }^{12}$ But further validation and consistency checks should certainly be conducted before these indicators can be classified as achieving adequate cross-sectional validity.

\footnotetext{
${ }^{10}$ Similarly, Studdert, Frongillo, and Valois's survey (2001) of Jakartan mothers found that some terms-such as the term "balanced diet"- translated very poorly to that context.

${ }^{11}$ We should add a caution regarding overinterpretation of the correlation coefficients between the food security indicators, considering that estimates of (food) expenditure, calorie consumption, and dietary diversity are derived from the same module in the surveys that likely contributes to strong correlations.

${ }^{12}$ One proposed means of improving subjective data is to use "anchoring vignettes" to elicit common reference frames (King et al. 2004). Other response biases could also be reduced through assurances of confidentiality and informing respondents that their answers to these question have no bearing on their qualification for transfer schemes.
} 


\section{Intertemporal Validity}

We know of very few analyses that test the performance of subjective indicators in gauging the impacts of shocks or seasonal shortfall. Using the Gallup World Poll indicator of "problems affording food," Headey (forthcoming) conducted some basic tests to see whether within-country changes in this indicator were significantly explained by real per capita GDP growth. He found a highly significant and negative effect of economic growth on changes in subjective food insecurity, but he also noted the low explanatory power of the regression, suggesting that measurement error was sizable. Indeed, many countries saw implausibly large changes in subjective food insecurity, implying that either the specific question or the survey itself was inducing measurement error or response biases.

More generally, there is a significant problem with interpreting changes in subjective indicators. For example, Helen Keller International uses the HFIAS in combination with anthropometric indicators for women and children in the Food Security and Nutrition Surveillance Project in Bangladesh. The HFIAS suggested that household food insecurity increased by a remarkable 31 percentage points (or 69 percent) between the first quarter of 2010 and the first quarter of 2011 (from 45.1 percent to 76.1 percent), possibly as a result of food price surges (HKI 2011). But is it plausible that the latent variablefood insecurity - really increased by such a large amount? Objective indicators suggest otherwise. The proportion of nonpregnant mothers in reproductive age with a BMI below 18.5 increased by almost five percentage points (or by 21 percent, from 22.7 to 27.5 percent). The prevalence of acute malnutrition (measured using weight-for-height $\mathrm{z}$-scores) among preschool children rose by almost three percentage points (from 7.6 percent to 10.3 percent). In contrast the prevalence of chronic child malnutrition (measured using height-for-age z-scores) declined by more than three percentage points (or by 7 percent, from 44.7 percent to 41.4 percent). So there are some anthropometric indications of rising food and nutrition insecurity, but a 31-percentage-point increase seems far too high.

\section{Nutritional Relevance}

In principle, an attractive feature of subjective indicators is that they can be asked of individuals as well as of households, although in practice questions asked about the household are more common (as in the HFIAS and Gallup questions). One underexplored issue is whether there may be response biases pertaining to individual versus household information. For example, questions about the food security of young children need to be asked of parents, who may be unwilling to admit that their children are inadequately fed. Similarly, previous research has shown that men and women within the same household can give very different answers to common questions about financial security, suggesting that gender biases could constitute an important issue for individual-level subjective questions (Breunig et al. 2007).

Are subjective indicators good predictors of malnutrition? There seems to be mixed evidence on this front. A recent paper by Kac et al. (2012) found that severe food insecurity - as measured by the HFIAS - was in fact a strong predictor of overweight prevalence in female adolescents aged 15 to 19 years. No less disturbing, a study of one particular district of Nepal found no association between HFIASbased food security and child malnutrition indicators (Osei et al. 2010). In contrast, a recent study in a rural area of Tanzania did find significant associations between the HFIAS and nutrition outcomes (Cordeiro et al. 2012). Another very recent study of the nutritional performance of HFIAS indicators in rural areas of Bangladesh, Ethiopia, and Vietnam by Ali, Tedla, and Headey (2012) found much stronger correlations (using a common questionnaire). Table 5.1 shows bivariate odds ratios from this study, along with confidence intervals. In all cases, higher degrees of food insecurity predict significantly higher rates of stunting and underweight prevalence, although only in Bangladesh is wasting explained by severe food insecurity. These multicountry results tend to suggest that the HFIAS does impart nutrition-relevant information in cross-sectional comparisons in relatively poor countries, but the association with obesity in Brazil again raises concerns about cross-country comparability of subjective indicators. 
Table 5.1-Bivariate associations (odds ratios) between HFIAS scores and stunting, undernutrition, and wasting in children six to 59 months of age

\begin{tabular}{|c|c|c|c|c|c|c|}
\hline \multicolumn{7}{|c|}{ Dependent variable $=$ Stunting prevalence } \\
\hline & \multicolumn{2}{|c|}{ Bangladesh $(n=3,310)$} & \multicolumn{2}{|c|}{ Ethiopia $(n=2,087)$} & \multicolumn{2}{|c|}{ Vietnam $(n=3,047)$} \\
\hline & $O R$ & $\mathrm{Cl}$ & OR & Cl & OR & $\mathrm{Cl}$ \\
\hline Food secure & 1 & & 1 & & 1 & \\
\hline Mildly insecure & $1.67^{* * *}$ & {$[1.27,2.21]$} & 1.18 & {$[0.92,1.50]$} & $1.44^{* *}$ & {$[1.14,1.84]$} \\
\hline Moderately insecure & $1.72^{* * *}$ & {$[1.39,2.12]$} & $1.38^{* *}$ & {$[1.13,1.69]$} & $1.85^{* * *}$ & {$[1.47,2.31]$} \\
\hline Severely insecure & $2.36^{\star * *}$ & {$[1.91,2.91]$} & $1.58^{* * *}$ & {$[1.23,2.04]$} & $1.65^{\star *}$ & {$[1.17,2.33]$} \\
\hline \multicolumn{7}{|c|}{ Dependent variable $=$ Underweight prevalence } \\
\hline & \multicolumn{2}{|c|}{ Bangladesh $(n=3,363)$} & \multicolumn{2}{|c|}{ Ethiopia $(n=2,339)$} & \multicolumn{2}{|c|}{ Vietnam $(n=3,046)$} \\
\hline & OR & $\mathrm{Cl}$ & OR & $\mathrm{Cl}$ & OR & $\mathrm{Cl}$ \\
\hline Food secure & 1 & & 1 & & 1 & \\
\hline Mildly insecure & $1.50^{* *}$ & {$[1.14,1.97]$} & $1.34^{*}$ & {$[1.02,1.77]$} & $1.79^{* * *}$ & {$[1.38,2.33]$} \\
\hline Moderately insecure & $1.42^{* *}$ & {$[1.15,1.75]$} & $1.39^{* *}$ & {$[1.11,1.74]$} & $2.14^{* * *}$ & {$[1.67,2.74]$} \\
\hline Severely insecure & $2.01^{* * *}$ & {$[1.64,2.47]$} & $1.90^{* * *}$ & {$[1.45,2.50]$} & $1.78^{* *}$ & {$[1.21,2.61]$} \\
\hline \multicolumn{7}{|c|}{ Dependent variable $=$ Wasting prevalence } \\
\hline & \multicolumn{2}{|c|}{ Bangladesh $(n=3,323)$} & \multicolumn{2}{|c|}{ Ethiopia $(n=2,329)$} & \multicolumn{2}{|c|}{ Vietnam $(n=3,044)$} \\
\hline & OR & $\mathrm{Cl}$ & OR & $\mathrm{Cl}$ & OR & $\mathrm{Cl}$ \\
\hline Food secure & 1 & & 1 & & 1 & \\
\hline Mildly insecure & 1.19 & {$[0.84,1.68]$} & 1.21 & {$[0.73,2.01]$} & 1.03 & {$[0.64,1.66]$} \\
\hline Moderately insecure & 1.07 & {$[0.82,1.40]$} & 1.13 & {$[0.73,1.73]$} & $1.64^{*}$ & {$[1.10,2.45]$} \\
\hline Severely insecure & $1.58^{* * *}$ & {$[1.24,2.01]$} & 1.22 & {$[0.72,2.06]$} & 1.3 & {$[0.68,2.49]$} \\
\hline
\end{tabular}

Source: Ali, et al. (2012).

Notes: $+p<0.10 . * p<0.05 . * * p<0.01 . * * * p<0.001$.

$\mathrm{OR}=$ odds ratio $\mathrm{CI}=$ confidence interval. 


\section{CONCLUSIONS AND IMPLICATIONS FOR IMPROVING FOOD SECURITY MEASUREMENT SYSTEMS}

\section{Summary and Indicator Scoring}

Despite widespread dissatisfaction with common food security indicators and measurement systems, very few studies have attempted to rigorously justify improvements. In this paper our first objective was to show that an ideal food security indicator - or suite of indicators - must satisfy a range of key criteria. Much previous research has focused on the issue of cross-sectional validity, through correlation analysis. To this we added increased emphasis on intertemporal dimensions beyond the ability to track slowmoving trends. This includes the capacity to gauge the impacts of major shocks, as well as seasonal effects. In addition, a large body of literature now persuasively demonstrates the instrumental importance of early childhood and maternal nutrition, adding nutritional relevance as a very important criterion for effective food security measurement.

Table 6.1 summarizes our findings on the usefulness of the four types of food security indicators, by each of these criteria. We also assign scores for whether we deem the indicator useful ( 2 points), potentially useful ( 1 point), or of limited use ( 0 points) for each criterion, and we take the sum of these scores as a rough indication of how close the indicator type is to the ideal. Admittedly, one could attach more or less weight to different dimensions; our equal weighting is arbitrary, but at least transparent.

Table 6.1 illustrates why we come down quite heavily in favor of dietary diversity as a class of indicator with considerable potential. In fact, dietary diversity indicators are the only class of indicators that has at least some usefulness according to each criterion. They are nutrition relevant in that they capture both macro- and micronutrient adequacy at least in a general way, in that they are measurable at the individual level, and in that they correlate well with nutritional outcomes. They appear to have considerable potential for gauging the impacts of shocks and seasonality, not only because dietary diversity is sensitive to shocks, but also because they are cheap enough to be collected at high frequency. Within-country dietary diversity increases with income in a more linear manner than calorie consumption alone. It is perhaps less clear that dietary diversity can be easily measured across countries. We found that even a very simple indicator of dietary diversity calculated from the FAO food balance sheets performed just as well as any other cross-country indicator in terms of cross-correlations with other food security indicators and anthropometric indicators of child malnutrition. So, dietary diversity indicators have substantial scope to add more value to food security measurement, especially if they can be refined and improved, rendered more comparable across populations, and measured more frequently over time.

We are much more skeptical about subjective/experiential indicators. Increasingly popular indicators - such as the HFIAS scale - admittedly share with dietary diversity indicators some desirable properties. They include the potential to focus on individuals, to pose questions on both macro- and micronutrients, and (because of cost-effectiveness) to be conducted at sufficient frequency to be useful in picking up shocks and exploring seasonality issues. However, the basic statistical validity and consistency of subjective indicators has yet to be convincingly established. Some existing evidence suggests that they lack validity (including cross-country comparability) and that they are highly sensitive to framing effects, question ordering, and other response biases (Deaton 2011; Deitchler et al. 2010; Headey forthcoming). Future research should therefore look at test-retest reliability as well and explore the highly problematic issue of response biases. With the rapid expansion of social safety nets in the developing world, response biases could be even more problematic in the future as respondents face stronger incentives to exaggerate their food insecurity.

Finally, we also rank calorie deprivation and poverty indictors quite poorly. Within countries, calorie deprivation and poverty indicators are measured from the same infrequent datasets and hence suffer many of the same problems including lack of individual-level data and a limited capacity to assess shocks and seasonality. Even for cross-country comparisons and trends there are important limitations, especially with the much criticized FAO indicator of "hunger." We rank poverty indicators slightly higher than calorie deprivation indicators, but we acknowledge that this is partly a matter of judgment given controversies over the international measurement of poverty, as well as the questionable nutritional relevance of poverty indicators. 
Table 6.1-Usefulness of food and nutrition indicators in gauging the impacts of shocks: A score sheet

\begin{tabular}{|c|c|c|c|c|}
\hline & \multicolumn{4}{|c|}{ USEFULNESS OF INDICATORS: "LIMITED" = 0 points; "POTENTIALLY" = 1 point; "USEFUL" = 2 points } \\
\hline Criterion & Calorie availability & Poverty & Dietary diversity & Subjective/experiential \\
\hline \multicolumn{5}{|l|}{ Cross-section } \\
\hline Across countries & $\begin{array}{c}\text { POTENTIALLY } \\
\text { Usefulness limited by } \\
\text { concerns over accuracy of } \\
\text { FAO methods }\end{array}$ & USEFUL & $\begin{array}{l}\text { POTENTIALLY } \\
\text { Further research on cross- } \\
\text { country comparisons } \\
\text { required }\end{array}$ & $\begin{array}{l}\text { LIMITED } \\
\text { Constrained by response } \\
\text { biases and lack of common } \\
\text { reference frame } \\
\text { LIMITED }\end{array}$ \\
\hline Within countries & USEFUL & USEFUL & USEFUL & $\begin{array}{l}\text { Constrained by response } \\
\text { biases and lack of common } \\
\text { reference frame }\end{array}$ \\
\hline \multicolumn{5}{|l|}{ Intertemporal } \\
\hline $\begin{array}{l}\text { Gauges welfare } \\
\text { trends? }\end{array}$ & $\begin{array}{l}\text { POTENTIALLY } \\
\text { Limited by changing calorie } \\
\text { requirements and low } \\
\text { calorie demand elasticities }\end{array}$ & USEFUL & $\begin{array}{l}\text { USEFUL } \\
\text { Further research on cross- } \\
\text { country comparisons } \\
\text { required }\end{array}$ & $\begin{array}{l}\text { LIMITED } \\
\text { Constrained by response } \\
\text { biases and lack of common } \\
\text { reference frame }\end{array}$ \\
\hline $\begin{array}{l}\text { Gauges impacts } \\
\text { of shocks? }\end{array}$ & $\begin{array}{l}\text { LIMITED } \\
\text { Not collected frequently; } \\
\text { limited to simulation } \\
\text { analysis }\end{array}$ & $\begin{array}{l}\text { LIMITED } \\
\text { Not collected frequently; } \\
\text { limited to simulation analysis }\end{array}$ & $\begin{array}{l}\text { POTENTIALLY } \\
\text { Cheap to collect, so can be } \\
\text { measured at high frequency }\end{array}$ & $\begin{array}{c}\text { POTENTIALLY } \\
\text { Cheap to collect, so can be } \\
\text { measured at high frequency; } \\
\text { can ask retrospective } \\
\text { questions } \\
\text { POTENTIALLY }\end{array}$ \\
\hline $\begin{array}{l}\text { Gauges } \\
\text { seasonality? }\end{array}$ & LIMITED & LIMITED & $\begin{array}{l}\text { POTENTIALLY } \\
\text { Cheap to collect, so can be } \\
\text { measured at high frequency }\end{array}$ & $\begin{array}{c}\text { Cheap to collect, so can be } \\
\text { measured at high frequency; } \\
\text { can ask retrospective } \\
\text { questions }\end{array}$ \\
\hline \multicolumn{5}{|l|}{ Nutrition } \\
\hline $\begin{array}{l}\text { Measured at the } \\
\text { individual level? }\end{array}$ & $\begin{array}{c}\text { LIMITED } \\
\text { Lack of individual data }\end{array}$ & $\begin{array}{c}\text { LIMITED } \\
\text { Lack of individual data }\end{array}$ & $\begin{array}{l}\text { USEFUL } \\
\text { Can be asked of individuals } \\
\text { as well as households }\end{array}$ & $\begin{array}{l}\text { USEFUL } \\
\text { Can be asked of individuals } \\
\text { as well as households }\end{array}$ \\
\hline $\begin{array}{l}\text { Micro- and } \\
\text { macronutrients? }\end{array}$ & $\begin{array}{l}\text { POTENTIALLY } \\
\text { Macronutrients only }\end{array}$ & $\begin{array}{c}\text { POTENTIALLY } \\
\text { Micronutrient needs not yet } \\
\text { specifically incorporated }\end{array}$ & $\begin{array}{l}\text { USEFUL } \\
\text { Can be asked of individuals } \\
\text { as well as households }\end{array}$ & $\begin{array}{c}\text { POTENTIALLY } \\
\text { Can ask about quality of diet, } \\
\text { but lack of common } \\
\text { reference frame }\end{array}$ \\
\hline Total score (14) & $5 / 14(36 \%)$ & $7 / 14(50 \%)$ & First: $11 / 14$ (80\%) & $5 / 14(36 \%)$ \\
\hline
\end{tabular}




\section{Implications for Improving Food Security Measurement}

A further implication of Table 6.1 and the conclusions drawn in this paper is that the greatest deficiencies in existing approaches to food security measurement are their incapacity to gauge shocks and their unsatisfactory basic nutritional relevance. It therefore behooves us to at least briefly discuss how such gaps could be filled.

Improving the nutritional relevance of food security measurement surely means using indicators that capture both macro- and micronutrient consumption, that can be measured at the individual level, and that give some sense of acute food insecurity (such as seasonal shortfalls or consumption shocks). Dietary diversity indicators seem to be useful to some extent in all three of these dimensions, at least if they can be measured with sufficient frequency. The nutritional relevance of food security indicators can also be maximized by co-measuring food security and nutrition indicators. This is fast becoming the practice with the World Bank's Living Standards Measurement Surveys, including the new Integrated Surveys on Agriculture project. The USAID-funded Demographic Health Surveys, the United Nations' Multiple Indicator Clusters Surveys, and various WFP surveys also collect standard nutrition indicators and some kind of dietary diversity indicators.

For cross-country purposes, we would argue that these organizations should consider measuring dietary diversity in a common way and in a manner that maximizes cross-country comparability. We have often informally heard the argument that dietary diversity cannot be measured across countries because of insurmountable differences in consumption patterns. This seems an implausible argument. Indeed, much more severe problems plague estimates of purchasing power parities (that is, estimating cross-country price differences across very different consumption bundles), which are absolutely essential to measuring poverty across countries (Deaton and Dupriez 2011). ${ }^{13}$ That more considerable challenge has not stopped efforts in poverty measurement, nor should it prevent attempts to improve the measurement of dietary quality across countries. If anything, the nutritional content of foods offers a much more intuitive means of comparing consumption patterns than price information. Hence a practical suggestion is for these key agencies to develop a common and internationally comparable dietary quality indicator and to further coordinate food and nutrition security surveys so as to maximize country coverage.

Another major knowledge gap — pertaining to impacts of shocks and seasonal shortfalls — will be more costly to fill, as it ultimately requires additional surveys carried out more frequently along the lines of the Nutrition Surveillance System surveys conducted in Indonesia and Bangladesh. ${ }^{14}$ These kinds of surveys yield important insights into the dynamics of food insecurity and are certainly useful for food security monitoring (Bloem, Moench-Pfanner, and Panagides 2003), but they are also costly to implement. Hence we would argue that they should be prioritized in countries that are highly exposed to shocks. The extent of exposure could be measured by dependence on humanitarian assistance, by exposure to natural disasters and seasonal shortfalls in general, and by baseline levels of chronic food and nutrition insecurity. These criteria would help to target resources to the countries or regions where highfrequency food and nutrition security measurement is most needed. ${ }^{15}$ The WFP and other humanitarian and development agencies would be natural proponents for such surveys, and actually the WFP already uses sentinel site surveys in a limited number of countries.

Although the expanded use of high-frequency surveys would involve substantial costs, we have several reasons for arguing that the benefits of the measurement system would ultimately exceed the costs by a healthy margin. First, information communication technologies will surely have a substantive effect in reducing the costs of data collection and in improving the timeliness of their dissemination. Second,

\footnotetext{
${ }^{13}$ For example, how does one compare price levels between the Cameroon, where cassava is a key staple, and India, where it is not? We would argue that the nutritional content of food actually offers a much easier means of ensuring cross-country comparability than prices. Yet the nutrition and food security communities often seem to feel that there is insufficient comparability.

${ }^{14}$ This recommendation is essentially along the sentinel systems advocated by Barrett (2010).

${ }^{15}$ Although there are a large number of developing countries in the world, a subset of developing countries are much more exposed to natural disasters and economic volatility than others. This is evident from data on food aid receipts and estimates of the number of people affected by disasters, produced by EM-DAT (2012).
} 
climate change research suggests that many already vulnerable regions could be much more exposed to these shocks in the future, contributing to rising costs of inaction (IPCC 2012). For example, recent climate research in the Horn of Africa suggests droughts have already become more common on the back of a much warmer India Ocean, and will continue to do so in the future (Funk et al. 2008). Yet the data that feed into the monitoring of recurrent and increasingly severe droughts in that region-including the exceptionally severe drought of 2011 - are infrequently collected and more conjectural than they need to be. ${ }^{16}$ Highly vulnerable regions like the Horn of Africa, to which many millions of dollars of humanitarian assistance are directed annually, surely merit better monitoring of food and nutrition security.

\footnotetext{
${ }^{16}$ In the 2011 drought in the Horn of Africa, major humanitarian agencies (such as the United Nations Office for the Coordination of Humanitarian Affairs, the WFP, and USAID) estimated that around 14 million people in four countries were in need of humanitarian assistance. In fact, it is quite difficult to ascertain how those specific numbers were obtained. However, the WFP was extremely helpful in sharing details of its methods. Specifically, it typically uses Emergency Food Security Assessments (EFSAs) of crisis situations, and its handbook on conducting EFSAs is available on the Web (www.wfp.org/content/emergency-food-security-assessment-handbook). We were informed that EFSAs vary a lot by context in terms of being rapid or in depth, in terms of using on quantitative or qualitative data, and in terms of what information is collected and what existing data are available. For example, an EFSA in Bangladesh primarily relied on focus group interviews and some collected market price data. Interestingly, that EFSA also used some baseline data from the Bangladesh Nutrition Surveillance System. EFSAs in South Sudan and Senegal had more quantitative data, but the nature of those data varied substantially across the two countries. In South Sudan the WFP was using sentinel sites, as well as a range of other household survey and census data. In Senegal a relatively small survey of 552 households was conducted in affected areas. Our perception is that this flexible approach is sensible given existing data constraints and limited resources, but our argument is that more highfrequency data could and should be collected in all but the most volatile environments. Indeed, high-frequency surveys should also be thought of as a capacity-building instrument for the countries involved.
} 


\section{REFERENCES}

Ali, D., K.K. Saha, P. Nguyen, M. Tedla, P. Menon, R. Rawat and M.T. Ruel. 2012. Is household food insecurity associated with child undernutrition? A multi-country study using data from Bangladesh, Ethiopia and Vietnam. IFPRI Discussion Paper, International Food Policy Research Institute (IFPRI), Washington DC.

Arimond, M., and M. Ruel. 2006. "Dietary Diversity Is Associated with Child Nutritional Status: Evidence from 11 Demographic and Health Surveys." Journal of Nutrition 134: 2579-2585.

Barrett, C. B. 2010. "Measuring Food Insecurity." Science 327: 825-828.

Beegle, K., J. De Weerdt, J. Friedman, and J. Gibson. 2012. "Methods of Household Consumption Measurement through Surveys: Experimental Results from Tanzania." Journal of Development Economics 98 (1): 3-18.

Block, S. A., L. Kiess, P. Webb, S. Kosen, R. Moench-Pfanner, M. W. Bloem, and C. P. Timmer. 2004. "Macro Shocks and Micro Outcomes: Child Nutrition during Indonesia's Crisis." Economics and Human Biology 2 (1): $21-44$.

Bloem, M. W., R. Moench-Pfanner, and D. Panagides. 2003. Health and Nutritional Surveillance for Development. Singapore: Helen Keller Worldwide.

Bloem, M. W., S. de Pee, and I. Darnton-Hill. 2005. "Micronutrient Deficiencies and Maternal Thinness: First Chain in the Sequence of Nutrition and Health Events in Economic Crises." In Preventive Nutrition: The Comprehensive Guide for Health Professionals, 3rd ed., edited by A. Bendich and R. J. Deckelbaum. Totowa, NJ, US: Humana Press.

Bouis, H. E. 1994. "The Effects of Income on Demand for Food in Poor Countries: Are Our Food Databases Giving Us Reliable Estimates?" Journal of Development Economics 44 (1): 199-220.

Bouis, H., L. Haddad, and E. Kennedy. 1992. "Does It Matter How We Survey Demand for Food? Evidence from Kenya and the Philippines." Food Policy 17 (6): 349-360.

Breunig, R., D. Cobb-Clark, X. Gong, and D. Venn. 2007. "Disagreement in Australian Partners' Reports of Financial Difficulty." Review of Economics of the Household 5 (1): 59-82.

Brinkman, H.-J., S. de Pee, I. Sanogo, L. Subran, and M. W. Bloem. 2010. "High Food Prices and the Global Financial Crisis Have Reduced Access to Nutritious Food and Worsened Nutritional Status and Health." Journal of Nutrition 140: 153S-161S.

Coates, J., A. Swindale, and P. Bilinsky. 2007. Household Food Insecurity Access Scale (HFIAS) for Measurement of Food Access: Indicator Guide. Food and Nutrition Technical Assitance (FANTA) project. Washington, DC: United States Agency for International Development.

Cordeiro, L. S., P. E. Wilde, H. Semu, and F. J. Levinson. 2012. "Household Food Security Is Inversely Associated with Undernutrition among Adolescents from Kilosa, Tanzania." Journal of Nutrition 142 (9): 1741-1747.

de Haen, H., S. Klasen, and M. Qaim. 2011. "What Do We Really Know? Metrics for Food Insecurity and Undernutrition." Food Policy 36 (6): 760-769.

de Hoyos, R., and D. Medvedev. 2009. Poverty Effects of Higher Food Prices: A Global Perspective. Policy Research Working Paper 4887. Washington, DC: World Bank.

Deaton, A. 1989. "Rice Prices and Income Distribution in Thailand: A Non-parametric Analysis." Economic Journal 99: 1-37.

. 2010. "Price Indexes, Inequality, and the Measurement of World Poverty." Presidential Address to the American Economic Association, Atlanta, January 4.

.2011. The Financial Crisis and the Well-Being of America. NBER Working Paper 17128. Cambridge, MA, US: National Bureau of Economic Research.

Deaton, A., and J. Drèze. 2002. "Poverty and Inequality in India: A Re-Examination." Economic and Political Weekly. Special articles, 3729-3748. 
. 2009. "Nutrition in India: Facts and Interpretations." Economic and Political Weekly 44 (7): 42-65.

Deaton, A., and O. Dupriez. 2011. "Purchasing Power Parity Exchange Rates for the Global Poor." American Economic Journal: Applied Economics 3 (2): 137-166.

Deitchler, M., T. Ballard, A. Swindale, and J. Coates. 2010. Validation of a Measure of Household Hunger for Cross-Cultural Use. Food and Nutrition Technical Assistance II (FANTA-2) project technical report. Washington, DC: US Agency for International Development.

EM-DAT (Emergency Events Database). 2012. EM-DAT: The OFDA/CRED International Disaster Database. Brussels: www.em-dat.net.

FAO (Food and Agriculture Organization of the United Nations). 1996. Rome Declaration on World Food Security and World Food Summit Plan of Action. www.fao.org/DOCREP/003/W3613E/W3613E00.HTM.

2003. Methodology for the Measurement of Food Deprivation. Rome.

.2009. The State of Food Insecurity in the World 2008. Rome: Food and Agriculture Organisation (FAO).

. 2011. The State of Food Insecurity in the World: Economic Crises-Impacts and Lessons Learned. Rome.

. 2011. The State of Food Insecurity in the World: How Does International Price Volatility Affect Domestic Economies and Food Security? Rome.

Frankenberg, E., D. Thomas, and K. Beegle. 1999. The Real Costs of Indonesia's Economic Crisis: Preliminary Findings from the Indonesia Family Life Survey. Santa Monica, CA, US: RAND.

Funk, C., M. D. Dettinger, J. C. Michaelsen, J. P. Verdin, M. E. Brown, M. Barlow, and A. Hoell. 2008. "Warming of the Indian Ocean Threatens Eastern and Southern African Food Security but Could Be Mitigated by Agricultural Development." Proceedings of the National Academy of Sciences 105 (32): 11081-11086.

Gabbert, S., and H. P. Weikard. 2001. "How Widespread Is Undernourishment? A Critique of Measurement Methods and New Empirical Results." Food Policy 26: 209-228.

Hartini, T. N. S., A. Winkvist, L. Lindholm, H. Stenlund, V. Persson, D. S. Nurdiati, and A. Surjono. 2003a. "Nutrient Intake and Iron Status of Urban Poor and Rural Poor without Access to Rice Fields Are Affected by the Emerging Economic Crisis: The Case of Pregnant Indonesian Women." European Journal of Clinical Nutrition 57: 654-666.

Hartini, T. N. S., A. Winkvist, L. Lindholm, H. Stenlund, and A. Surjono. 2003b. "Food Patterns during an Economic Crisis among Pregnant Women in Purworejo District, Central Java, Indonesia." Food and Nutrition Bulletin 24 (3): 256-267.

Hatloy, A., L. Torheim, and A. Oshaug. 1998. "Food Variety: A Good Indicator of Nutritional Adequacy of the Diet? A Case Study from an Urban Area in Mali, West Africa." European Journal of Clinical Nutrition 52 (12): 891-898.

Headey, D. Forthcoming. “The Impact of the Global Food Crisis on Self-Assessed Food Security.” World Bank Economic Review.

Headey, D., A. Chiu and S. Kadiyala. 2012. Agriculture's role in the Indian enigma: Help or hindrance to the malnutrition crisis? Food Security 4 (1): 87-102.

HKI. 2011. The Food Security and Nutrition Surveillance Project, Round 4: February-May 2011. Bulletin No. 2 , Helen Keller International, Bangladesh.

Hoddinott, J., and Y. Yohannes. 2002. Dietary Diversity as a Food Security Indicator. Food Consumption and Nutrition Division Discussion Paper. Washington, DC: International Food Policy Research Institute.

IPCC (Intergovernmental Panel on Climate Change). 2012. Managing the Risks of Extreme Events and Disasters to Advance Climate Change Adaptation. New York: Cambridge University Press.

Ivanic, M., and W. Martin. 2008. "Implications of Higher Global Food Prices for Poverty in Low-Income Countries.” Agricultural Economics 39 (s1): 405-416. 
Ivanic, M., W. Martin, and H. Zaman. 2011. Estimating the Short-Run Poverty Impacts of the 2010-11 Surge in Food Prices. Policy Research Working Paper 5633. Washington, DC: World Bank.

Jensen, R. T., and N. H. Miller. 2010. A Revealed Preference Approach to Measuring Undernutrition and Poverty Using Calorie Shares. NBER Working Paper 16555. Cambridge, MA, US: National Bureau of Economic Research.

Kac, G., G. Velásquez-Melendez, M. M. Schlüssel, A. M. Segall-Côrrea, A. A. Silva, and R. Pérez-Escamilla. 2012. "Severe Food Insecurity Is Associated with Obesity among Brazilian Adolescent Females." Public Health Nutrition 15 (10): 1854-1860.

Kennedy, G., T. Ballard, and M. C. Dop. 2011. Guidelines for Measuring Household and Individual Dietary Diversity. Rome: Food and Agriculture Organization of the United Nations.

Kennedy, G., M. R. Pedro, C. Seghieri, G. Nantel, and I. Brouwer. 2007. "Dietary Diversity Score Is a Useful Indicator of Micronutrient Intake in Non Breast-Feeding Filipino Children." Journal of Nutrition 13: 1-6.

King, G., C. J. L. Murray, J. A. Salomon, and A. Tandon. 2004. "Enhancing the Validity and Cross-Cultural Comparability of Measurement in Survey Research." American Political Science Review 98 (1): 191-207.

Maslow, A. H. 1943. “A Theory of Human Motivation.” Psychological Review 50 (4): 370-396.

Nabarro, D. 2010. "Nutrition Repositioned in the Development Agenda? Current Prospects for Scaling-Up Nutrition Outcomes.” Paper presented at the Annual Martin J. Forman Memorial Lecture, November 4, International Food Policy Research Institute, Washington, DC.

Ngwenya, E., and R. Ray. 2007. Changes in Indonesian Food Consumption Patterns and Their Nutritional Implications. UTAS Discussion Paper 2007-06. University of Tasmania, Department of Economics and Finance.

Nubé, M. 2001. "Confronting Dietary Energy Supply with Anthropometry in the Assessement of Undernutrition Prevalence at the Level of Countries." World Development 29 (7): 1275-1289.

OECD/FAO (Organization for Economic Cooperation and Development / Food and Agriculture Organization of the United Nations). 2009. OECD-FAO Agricultural Outlook 2009-2018. Geneva and Rome.

Osei, A., P. Pandey, D. Spiro, J. Nielson, R. Shrestha, Z. Talukder, V. Quinn, and N. Haselow. 2010. "Household Food Insecurity and Nutritional Status of Children Aged 6 to 23 Months in Kailali District of Nepal." Food and Nutrition Bulletin 31 (4): 483-494.

Pelletier, D. L., K. Deneke, Y. Kidane, B. Haile, and F. Negussie. 1995. "The Food-First Bias and Nutrition Policy: Lessons from Ethiopia." Food Policy 20 (4): 279-298.

Ruel, M. 2003. "Operationalizing Dietary Diversity: A Review of Measurement Issues and Research Priorities.” Journal of Nutrition 133: 3911S-3926S.

Savy, M., Y. Martin-Prevel, P. Traissac, S. Emyard-Duvernay, and F. Delpeuch. 2006. "Dietary Diversity Scores and Nutritional Status of Women Change during the Seasonal Food Shortage in Rural Burkina Faso." Journal of Nutrition 136: 2625-2632.

Skoufias, E. 2003. "Is the Calorie-Income Elasticity Sensitive to Price Changes? Evidence from Indonesia." World Development 31 (7): 1291-1307.

Smith, L. C. 1998. “Can FAO'S Measure of Chronic Undernourishment Be Strengthened?” Food Policy 23 (5): 425-445.

Smith, L. C., H. Alderman, and D. Aduayom. 2006. Food Insecurity in Sub-Saharan Africa: New Estimates from Household Expenditure Surveys. Research Report 146. Washington, DC: International Food Policy Research Institute.

Steyn, N. P., J. H. Nel, G. Nantel, G. Kennedy, and D. Labadarios. 2006. "Food Variety and Dietary Diversity Scores in Children: Are They Good Indicators of Dietary Adequacy?" Public Health Nutrition 9 (5): 644650 . 
Studdert, L. J., E. A. Frongillo, and P. Valois. 2001. "Household Food Security Was Prevalent in Java during Indonesia's Economic Crisis." Journal of Nutrition 131: 2685-2691.

Svedberg, P. 1999. “841 Million Undernourished?" World Development 27 (12): 2081-2098. . 2002. "Undernutrition Overestimated." Economic Development and Cultural Change 51 (1): 5-36.

Swindale, A., and P. Bilinsky. 2006a. Household Dietary Diversity Measurement of Household Food Access: Indicator Guide, version 2. Washington, DC: Food and Nutrition Technical Assistance Project. . 2006b. "Development of a Universally Applicable Household Food Insecurity Measurement Tool: Process, Current Status, and Outstanding Issues.” Journal of Nutrition 136 (5): 1449S-1452S.

Swinnen, J. 2010. The Right Price of Food: Reflections on the Political Economy of Policy Analysis and Communication. LICOS Discussion Paper 25910. Leuven, Belgium: LICOS Centre for Institutions and Economic Performance, University of Leuven.

Torheim, L., F. Ouattara, M. Diarra, F. Thiam, I. Barikmo, A. Hatloy and A. Oshaug. 2004. Nutrient adequacy and dietary diversity in rural Mali: association and determinants. European Journal of Clinical Nutrition 58: 594-604.

Torlesse, H., L. Kiess, and M. W. Bloem. 2003. "Association of Household Rice Expenditure with Child Nutritional Status Indicates a Role for Macroeconomic Food Policy in Combating Malnutrition." Journal of Nutrition 133: $1320-1325$.

USDA (US Department of Agriculture). 2009. Agricultural Projections to 2018. Washington, DC.

WFP (World Food Programme). 2008. Food Consumption Analysis: Calculation and Use of the Food Consumption Score. Rome.

Wiesmann, D., L. Bassett, T. Benson, and J. Hoddinott. 2009. Validation of the World Food Programme's Food Consumption Score and Alternative Indicators of Household Food Security. IFPRI Discussion Paper 00870. Washington, DC: International Food Policy Research Institute.

World Bank. 2008. International Comparison Program. http://siteresources.worldbank.org/ICPEXT/Resources/ICP_2011.html. Accessed September 23, 2012. . 2012. PovcalNET. http://iresearch.worldbank.org/PovcalNet/index.htm?3. 


\section{RECENT IFPRI DISCUSSION PAPERS}

\section{For earlier discussion papers, please go to www.ifpri.org/pubs/pubs.htm\#dp. All discussion papers can be downloaded free of charge.}

1224. Improved performance of agriculture in Africa south of the Sahara: Taking off or bouncing back. Alejandro Nin-Pratt, Michael Johnson, and Bingxin Yu, 2012.

1223. Review of input and output policies for cereals production in Pakistan. Abdul Salam, 2012.

1222. Supply and demand for cereals in Pakistan, 2010-2030. Hina Nazli, Syed Hamza Haider, and Asjad Tariq, 2012.

1221. The road to specialization in agricultural production: Evidence from Rural China. Yu Qin and Xiaobo Zhang, 2012.

1220. Change and diversity in smallholder rice-fish systems: Recent evidence from Bangladesh. Madan M. Dey, David J. Spielman, A.B.M. Mahfuzul Haque, Md. Saidur Rahman, and Rowena A. Valmonte-Santos, 2012.

1219. Is MERCOSUR's external agenda pro-poor?: An assessment of the European Union-MERCOSUR free-trade agreement on poverty in Uruguay applying MIRAGE. Carmen Estrades.

1218. Heterogeneous pro-poor targeting in India's Mahatma Gandhi national rural employment guarantee scheme. Yanyan Liu and Christopher B. Barrett, 2012.

1217. The impacts of public investment in and for agriculture: Synthesis of the existing evidence. Tewodaj Mogues, Bingxin Yu, Shenggen Fan, and Linden McBride, 2012.

1216. What determines public expenditure allocations?: A review of theories, and implications for agricultural public investment. Tewodaj Mogues, 2012.

1215. Nonlinear dynamics of livestock assets: Evidence from Ethiopia. Bjorn Van Campenhout and Stefan Dercon, 2012.

1214. An overview of Chinese agricultural and rural engagement in Tanzania. Deborah Bräutigam and Xiaoyang Tang, 2012.

1213. The partially liberalized cocoa sector in Ghana: Producer price determination, quality control, and service provision. Shashidhara Kolavalli, Marcella Vigneri, Haruna Maamah, and John Poku, 2012.

1212. Structural change in Argentina, 1935-60: The role of import substitution and factor endowments. Dario Debowicz and Paul Segal, 2012

1211. Traceability in a supply chain with repeated moral hazard. Alexander E. Saak, 2012.

1210. Managing transition in Yemen: An assessment of the costs of conflict and development scenarios for the future. Clemens Breisinger, Olivier Ecker, Perrihan Al Riffai, Wilfried Engelke, and Abdulmajeed Al-Bataly, 2012.

1209. Bangladesh rice trade and price stabilization: Implications of the 2007/08 experience for public stocks. Paul A. Dorosh and Shahidur Rashid, 2012.

1208. Analyzing intersectoral convergence to improve child undernutrition in India: Development and application of a framework to examine policies in agriculture, health, and nutrition. Rajani Ved and Purnima Menon, 2012.

1207. Branding and agricultural value chains in developing countries: Insights from Bihar, India. Bart Minten, K.M. Singh, and Rajib Sutradhar, 2012.

1206. Costly posturing: Relative status, ceremonies, and early child development in China. Xi Chen and Xiaobo Zhang, 2012.

1205. Should private storage be subsidized to stabilize agricultural markets after price support schemes are removed?: A general equilibrium analysis applied to European reforms. Fabienne Femenia, 2012.

1204. Mapping the contemporary fertilizer policy landscape in Malawi: A guide for policy researchers. Noora-Lisa Aberman, Michael Johnson, Klaus Droppelmann, Eva Schiffer, Regina Birner, and Peter Gaff, 2012.

1203. The economic consequences of excess men: Evidence from a natural experiment in Taiwan. Simon Chang and Xiaobo Zhang, 2012.

1202. The value of customized insurance for farmers in rural Bangladesh. Daniel Clarke, Narayan Das, Francesca de Nicola, Ruth Vargas Hill, Neha Kumar, and Parendi Mehta, 2012.

1201. Gender assessment of the agricultural sector in the Democratic Republic of the Congo. Catherine Ragasa, Annie KinwaMuzinga, and John Ulimwengu, 2012. 


\section{INTERNATIONAL FOOD POLICY RESEARCH INSTITUTE}

www.ifpri.org

IFPRI HEADQUARTERS

2033 K Street, NW

Washington, DC 20006-1002 USA

Tel.: +1-202-862-5600

Fax: +1-202-467-4439

Email: ifpri@cgiar.org

IFPRI ADDIS ABABA

P. O. Box 5689

Addis Ababa, Ethiopia

Tel.: + 251 (0) 11-617-2500

Fax: + 251 (0) 11-646-2927

Email: ifpri-addisababa@cgiar.org 